\title{
A Brain Tumor from a Posttransplant Lymphoproliferative Disorder in a Kidney Transplant Recipient
}

\author{
Jin Hyuk Paek, M.D. ${ }^{1}$, Yae Rim Kim, M.D. ${ }^{1}$, Mi Hyun Jang, M.D. ${ }^{1,2}$, Eun Ah Hwang, M.D., Ph.D. ${ }^{1,2}$, \\ Seung Yeup Han, M.D., Ph.D. ${ }^{1,2}$ and Sung Bae Park, M.D., Ph.D. ${ }^{1,2}$
}

Department of Internal Medicine, Keimyung University School of Medicine', Keimyung University Kidney Institute², Daegu, Korea

\begin{abstract}
Posttransplant lymphoproliferative disorder (PTLD) is a life-threatening complication from organ transplantation. PTLD usually manifests as a mass in the lymph node or an extranodal mass in solid organs, such as the liver, transplanted kidney, tonsil, bone marrow, or spleen. PTLD rarely involves the central nervous system (CNS); however, here we report a case of PTLD that manifested as a brain tumor after kidney transplantation. A 52-year-old man who started peritoneal dialysis due to autosomal dominant polycystic kidney disease, underwent kidney transplantation 4 years ago. After kidney transplantation, he took tacrolimus, mycophenolate mofetil, and steroids. He was admitted to our hospital, complaining of a severe headache. Brain magnetic resonance imaging showed a multifocal, irregular, and round enhancing mass in the left basal ganglia. He underwent a needle biopsy for the enhancing mass and the pathological diagnosis was diffuse large B cell lymphoma. After this mass was confirmed as PTLD by histologic diagnosis, the patient had a reduction in his immunosuppression regimen (including a change from tacrolimus to sirolimus) and was treated with chemotherapy for PTLD. After 20 days, the patient expired from sepsis. PTLD involving the CNS is a rare and serious complication associated with solid organ transplantation. PTLD should be included in the differential diagnosis of brain tumors in recipients of solid organ transplants.
\end{abstract}

Key Words: Posttransplant lymphoproliferative disorder, Kidney transplantation, Brain neoplasms 중심 단어: 림프 증식성 질환, 신장 이식, 뇌종양

\section{Introduction}

Posttransplant lymphoproliferative disorder (PTLD) is one of the life-threatening complications of organ transplantation. Its incidence varies, depending on the recipient's age, the type and intensity of immunosuppression, and the organ type transplanted. The incidence ranges from $1 \%$ after kidney transplantation to as high as $20 \%$ in small bowel recipients, and it is higher in children than adults(1). Few studies refer to the incidence of central nervous system (CNS) involvement in PTLD. CNS involvement was found in one case of 14 PTLD patients after kidney transplantation(2), and in $2 \sim 7 \%$ of posttransplant recipients, according to the

Correspondence : Seung Yeup Han, Department of Internal Medicine, Keimyung University School of Medicine, 56 Dalseong-ro, Jung-gu, Daegu 700-712, Korea

Tel: +82-53-250-7913, Fax: +82-53-253-7976

E-mail: hansy@dsmc.co.kr

Received: April 21, 2013, Revised: May 10, 2013,

Accepted : May 26, 2013 type of organ, in 500 autopsy cases(3). Treatment recommendations are not clearly established $(4,5)$ and prognosis of primary CNS lymphoma is poor as compared to systemic PTLD(4-6). Here, we report a case of PTLD manifested as brain tumor after kidney transplantation.

\section{Case Report}

A 52-year-old man who had received peritoneal dialysis for 6 years due to autosomal dominant polycystic kidney disease undergone kidney transplantation 4 years ago. After kidney transplantation, he was treated with tacrolimus $5 \mathrm{mg}$ daily, mycophenolate 1,250 mg daily, and deflazacort $3 \mathrm{mg}$ daily. He was admitted to our hospital complaining of severe headache. At presentation, the patient was hemodynamically stable. On general neurologic examination, there were no abnormalities. Heart, lungs, and abdominal examination was unremarkable. Ophthalmologic examination did not show any evidence of infection, inflammation, 
or neoplastic process. Laboratory tests showed the following values: white blood cell count $8,630 / \mu \mathrm{L}$; hemoglobin $13.2 \mathrm{~g} / \mathrm{dL}$; platelet count 213,000/ $\mu \mathrm{L}$; blood urea nitrogen $21 \mathrm{mg} / \mathrm{dL}$; serum creatinine $1.1 \mathrm{mg} / \mathrm{dL}$; lactate dehydrogenase $406.6 \mathrm{U} / \mathrm{L}$; and tacrolimus level $6.0 \mathrm{ng} / \mathrm{mL}$. Urinalysis showed red blood cell count of $8 \sim 10$ cells/high power field, negative for protein and white blood cell. Brain computed tomography showed brain tumor with adjacent edema and mass effect in left cerebral hemisphere (Fig. 1). Brain magnetic resonance imaging showed multifocal irregular round enhancing mass in left thalamus, basal ganglia, periventricular white matter, midbrain, pons, and middle cerebellar peduncle (Fig. 2). He underwent a needle biopsy for left thalamic enhancing mass. Histological examination of the tumor specimen found uniform large lymphocytes and immunohistochemisty stain of CD20, CD79a was positive, Ki-67 proliferation was about 30\% and glial fibrillary acidic protein was negative (Fig. 3). In tissue, Epstein-Barr virus (EBV) in situ hybridization was negative. Pathological diagnosis was diffuse large B cell lymphoma. Further laboratory results proved to be positive for EBV viral capsid antigen (VCA) IgG, EBV nuclear antigen IgG, and negative for EBV VCA IgM, EBV early antigen IgG, EBV polymerase chain reaction. Systemic fluorodeoxyglucose positron-emission tomography and systemic computed tomography showed

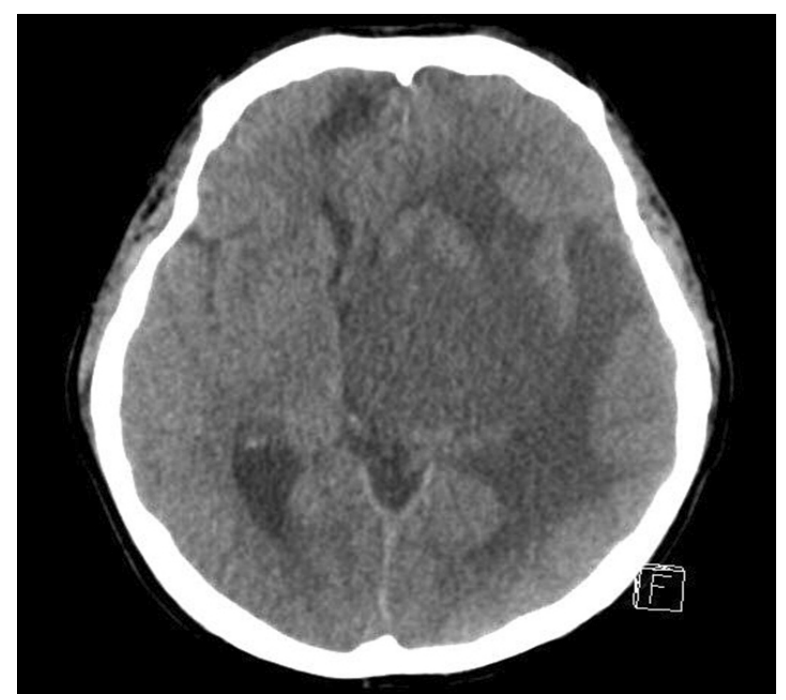

Fig. 1. Brain computed tomography shows brain tumor with adjacent edema and mass effect in left cerebral hemisphere. no lesions other than the brain tumors. After confirmed as PTLD by histologic diagnosis, tacrolimus, mycophenolate, and deflazacort were discontinued. He was prescribed sirolimus $2 \mathrm{mg}$ daily. He was treated with PTLD (methotrexate, procarbazine, vincristine, and dexamethasone). But he exipired after 20 days due to pneumonia sepsis.

\section{Discussion}

PTLD is the second most common malignancy after skin cancer among adult solid organ transplantation recipients. CNS involvement is rare, especially in isolation. A review of the Israel Penn International Transplant Tumor Registry indicated that $15 \%$ of patients with PTLD had CNS involvement; and, in half of those patients, the CNS was the only site of disease(7). In our center, 12 patients were diagnosed with PTLD among 1,013 kidney transplantation patients. Our patient was the only one who was diagnosed with CNS-PTLD.

The time from transplantation to the diagnosis of primary CNS-PTLD is 4.4 years. Twenty-three percentage of patients developed primary CNS-PTLD more than 10 years after transplantation and 35\% of patients developed primary CNS-PTLD within 1 year of transplantation(8). In our center, the median time from

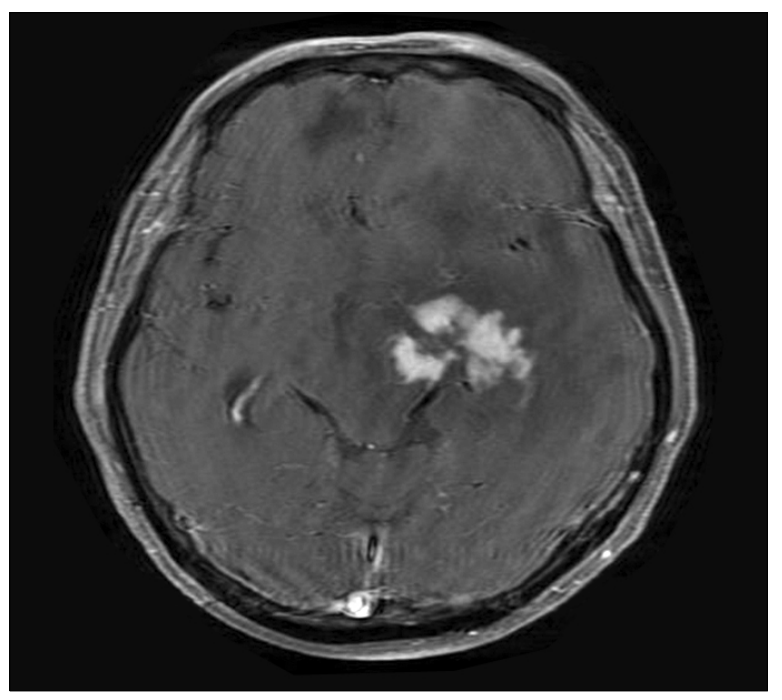

Fig. 2. Brain magnetic resonance imaging shows brain tumor involved in left thalamus, basal ganglia, periventricular white matter, midbrain, pons, and middle cerebellar peduncle. 

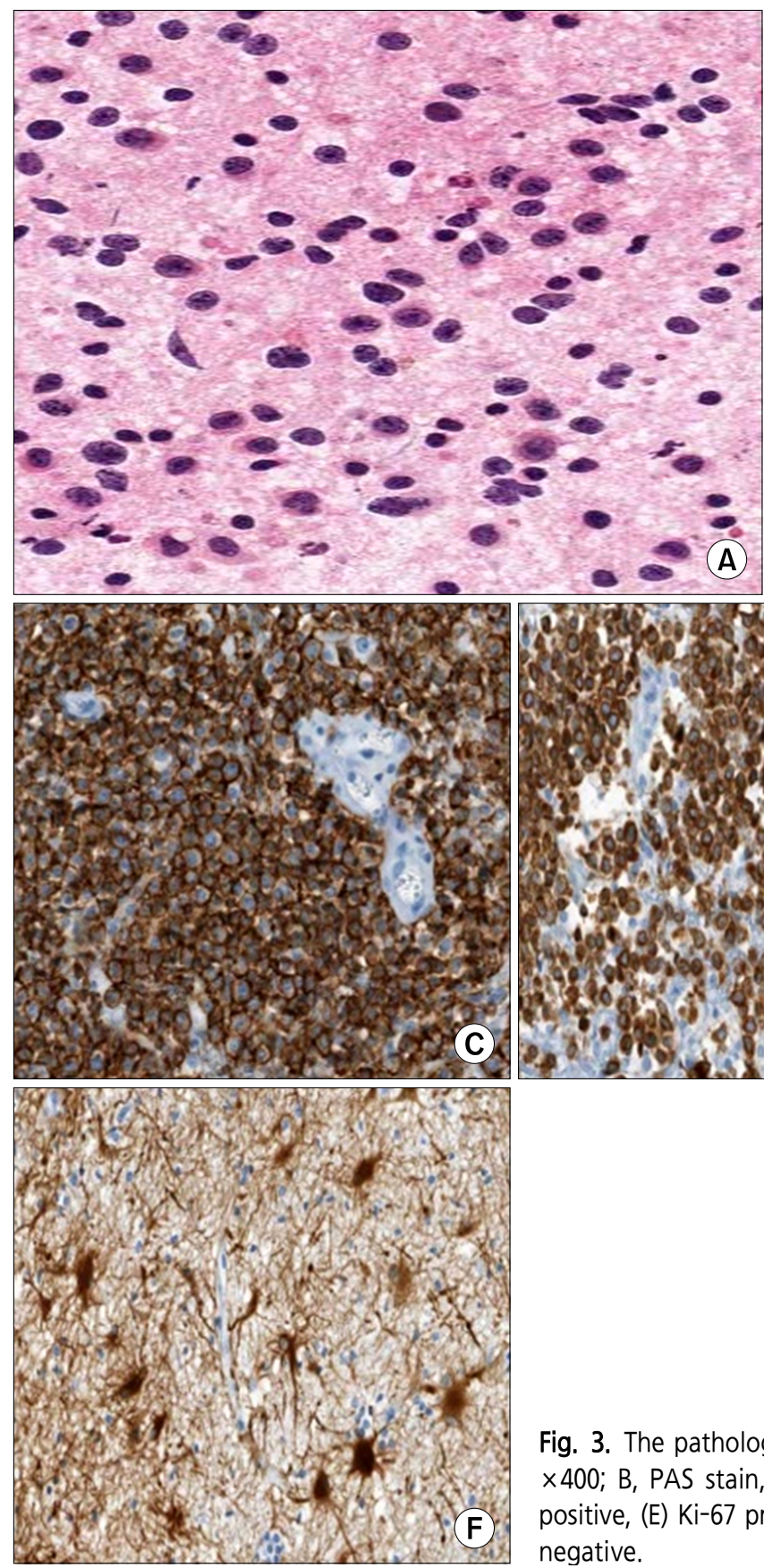
negative.
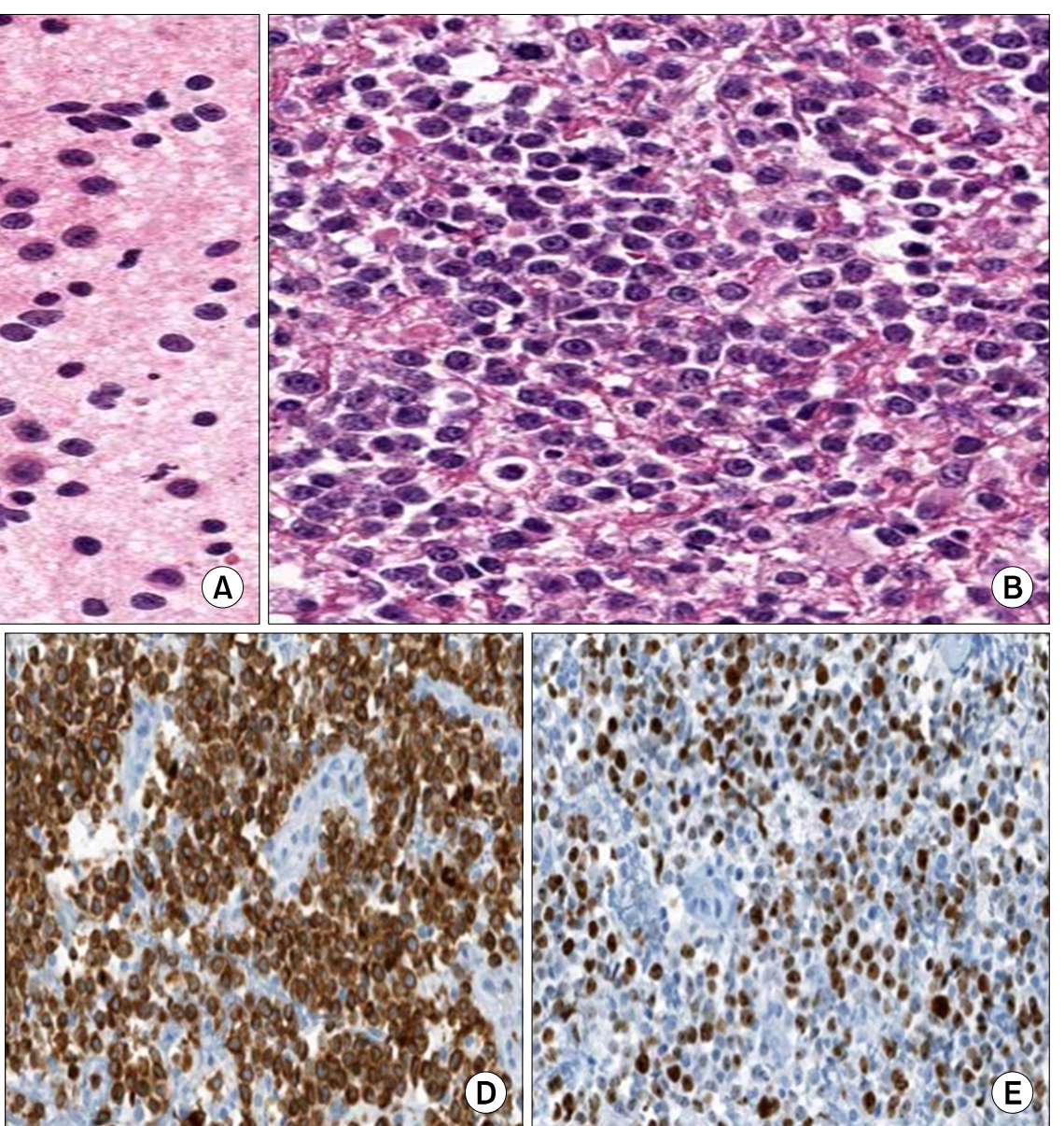

Fig. 3. The pathological examination showed uniform large lymphocytes ( $A$, HE stain, $\times 400$; B, PAS stain, x400). Immunohistochemistry stain of (C) CD20, (D) CD79a was positive, (E) Ki-67 proliferation was about $30 \%$ and (F) glial fibrillary acidic protein was transplantation to diagnosis of PTLD was 6.5 years. Our patient was diagnosed with CNS-PTLD 4 years after kidney transplantation.

The type and intensity of immunosuppression have been linked with PTLD risk. However, it is not clear which immunosuppressive agents are realted to PTLD risk. Wimmer et al.(9) noted that a triple immunosuppressive regimen including mycophenolate mofetil was considered to have the highest imposing impact on the posttransplant malignancies. Snanoudj et al.(10) also noted that several of their primary CNS-PTLD cases developed soon after immunosuppression regimens were changed to mycophenolate mofetil. However, Einollahi et al.(11) noted that the incidence of PTLD was significantly increased in patients receiving azathioprine when compared to patients receiving mycophenolate mofetil. Our patient received a triple immunosuppressive regimen including mycophenolate 
mofetil.

Histologically, monomorphic PTLD has a more advanced and aggressive form than polymorphic PTLD. Monomorphic PTLD consists of large, transformed, blastic cells with prominent nucleoli and basophilic cytoplasm. Most monomorphic PTLD can be classified as large $\mathrm{B}$ cell lymphomas under the revised EuropeanAmerican lymphoma classification(12). Polymorphic PTLD has been defined as atypical lymphoid infiltrates consisting of a heterogeneous cell population reflecting the full range of $\mathrm{B}$ cell maturation. The predominance of monomorphic type over the polymorphic type (100\% vs. 0\%) has been reported in CNS PTLD $(12,13)$. However, another study reported a contradictory result (21\% vs. 79\%)(10). In our case, the patient was diagnosed with monomorphic type PTLD classified as large B cell lymphoma.

EBV infection is a risk factor for developing PTLD and $60 \sim 80 \%$ of PTLD is positive for EBV infection. The provision of immunosuppressive therapy prevents cytotoxic T-lymphocytes to control proliferation of EBV-infected B-lymphocytes ultimately leading to transformation into PTLD(5). Primary infection of a previously EBV-seronegative patient during immunosuppression has been identified as a significant risk factor for the development of PTLD. This may occur through natural exposure or through transmission from an EBV-infected graft in a seronegative recipient(14). Our patient was not related to EBV infection.

There is no definitive treatment for CNS PTLD. The main treatment of CNS PTLD is reducing or discontinuing the immunosuppressive therapy. Chemotherapy such as cyclophosphamide, adriamycin, vincristine, and prednisolone and anti B cell antibody have been used in the treatment of non-CNS PTLD. However, CNS PTLD is considered resistant to these agents, because of the low drug permeability of the blood brain barrier(4). Nonetheless, recent data suggest that earlier use of rituximab may have favorable outcome $(5,15)$. Radiotherapy is usually effective used singly or in combination with other treatments. But modulation of immunosuppressive agents should always be considered before performing whole brain radiation $(10,12)$.
In conclusion, PTLD involving CNS is a rare and serious complication associated with solid organ transplantation. PTLD should be included in the differential diagnosis of brain tumors in recipients of solid organ transplantation.

\section{REFERENCES}

1) Taylor AL, Marcus R, Bradley JA. Post-transplant lymphoproliferative disorders (PTLD) after solid organ transplantation. Crit Rev Oncol Hematol 2005;56:155-67.

2) Saadat A, Einollahi B, Ahmadzad-Asl MA, Moradi M, Nafar M, Pourfarziani V, et al. Posttransplantation lymphoproliferative disorders in renal transplant recipients: report of over 20 years of experience. Transplant Proc 2007;39:1071-3.

3) Martinez AJ. The neuropathology of organ transplantation: comparison and contrast in 500 patients. Pathol Res Pract 1998;194:473-86.

4) Gerstner ER, Batchelor TT. Primary central nervous system lymphoma. Arch Neurol 2010;67:291-7.

5) Jagadeesh D, Woda BA, Draper J, Evens AM. Post transplant lymphoproliferative disorders: risk, classification, and therapeutic recommendations. Curr Treat Options Oncol 2012;13:122-36.

6) Evens AM, Roy R, Sterrenberg D, Moll MZ, Chadburn A, Gordon LI. Post-transplantation lymphoproliferative disorders: diagnosis, prognosis, and current approaches to therapy. Curr Oncol Rep 2010;12:383-94.

7) Buell JF, Gross TG, Hanaway MJ, Trofe J, Roy-Chaudhury P, First MR, et al. Posttransplant lymphoproliferative disorder: significance of central nervous system involvement. Transplant Proc 2005;37:954-5.

8) Cavaliere R, Petroni G, Lopes MB, Schiff D; International Primary Central Nervous System Lymphoma Collaborative Group. Primary central nervous system post-transplantation lymphoproliferative disorder: an International Primary Central Nervous System Lymphoma Collaborative Group Report. Cancer 2010;116:863-70.

9) Wimmer CD, Rentsch M, Crispin A, Illner WD, Arbogast H, Graeb C, et al. The janus face of immunosuppression: de novo malignancy after renal transplantation: the experience of the Transplantation Center Munich. Kidney Int 2007;71:1271-8.

10) Snanoudj R, Durrbach A, Leblond V, Caillard S, Hurault De Ligny B, Noel C, et al. Primary brain lymphomas after kidney transplantation: presentation and outcome. Transplantation 2003;76:930-7.

11) Einollahi B, Lessan-Pezeshki M, Nourbala MH, Simforoosh N, Pourfarziani V, Nemati E, et al. Posttransplant lymphoproliferative disorders in kidney transplant recipients: an Iranian multicenter experience. Iran J Kidney Dis 2008;2:227-33.

12) Castellano-Sanchez AA, Li S, Qian J, Lagoo A, Weir E, 
Brat DJ. Primary central nervous system posttransplant lymphoproliferative disorders. Am J Clin Pathol 2004; 121:246-53.

13) Phan TG, O'Neill BP, Kurtin PJ. Posttransplant primary CNS lymphoma. Neuro Oncol 2000;2:229-38.

14) Lim WH, Russ GR, Coates PT. Review of Epstein-Barr virus and post-transplant lymphoproliferative disorder post-solid organ transplantation. Nephrology (Carlton) 2006;11:355-66.

15) Traum AZ, Rodig NM, Pilichowska ME, Somers MJ. Central nervous system lymphoproliferative disorder in pediatric kidney transplant recipients. Pediatr Transplant 2006;10:505-12. 